Yi-Chao YIN

Hong-Zhong HUANG

Weiwen PENG

Yan-Feng LI

Jinhua Ml

\title{
AN E-BAYESIAN METHOD FOR RELIABILITY ANALYSIS OF EXPONENTIALLY DIS- TRIBUTED PRODUCTS WITH ZERO-FAILURE DATA
}

\section{METODA BAYESOWSKIEJ ESTYMACJI WARTOŚCI OCZEKIWANEJ DLA PRODUKTÓW O ROZKŁADZIE WYKŁADNICZYM WYKORZYSTUJĄCA DANE O NIEZAISTNIAŁYCH USZKODZENIACH}

\begin{abstract}
This paper investigate an E-Bayesian estimation as a reliability analysis method for the seekers to deal with the zero-failure life testing data. Firstly, we introduce an E-Bayesian estimation for the exponential distribution, and then propose a zero-failure model with assumptions. Using the proposed model, we set up a series of life tests for the seekers, and apply the E-Bayesian estimation on the observed zero-failure data to calculate the failure rate and reliability of the seekers. Finally, the reliability estimation results of the seekers demonstrate the performance of the proposed method.
\end{abstract}

Keywords: E-Bayesian estimation, exponential distribution, zero-failure data, failure rate, hierarchical Bayesian estimation.

\begin{abstract}
W pracy analizowano estymację bayesowska wartości oczekiwanej jako metodę analizy niezawodności urządzeń naprowadzajacych w przypadkach, gdy dane z badań trwałości sa danymi o uszkodzeniach niezaistniatych (zerowych). W pierwszej części pracy opisano E-estymację bayesowska dla rozkładu wykładniczego, a następnie zaproponowano model uszkodzeń niezaistniatych oraz opisano jego założenia. Wykorzystując zaproponowany model, zaprojektowano i zrealizowano serię badań trwałości urzadzeń naprowadzajacych jak również zastosowano E-estymację bayesowską w celu obliczenia intensywności uszkodzeń oraz niezawodności badanych urządzeń. Wyniki oceny niezawodności urządzeń naprowadzających potwierdzaja przydatność proponowanej metody.
\end{abstract}

Stowa kluczowe: estymacja bayesowska wartości oczekiwanej, rozkład wykładniczy, dane o niezaistniatych uszkodzeniach, intensywność uszkodzeń, hierarchiczna estymacja bayesowska.

\section{Introduction}

Reliability is the probability of a component or system working regularly. Reliability technology was firstly applied in the fields of nuclear industry, aviation and aerospace, and then was spread to the industries of electronic, metallurgy, mechanical and so on. The researches and analyses on the reliability theories and applications have lasted for decades. Now reliability has become one of the most important areas in the industry. With the improvement of reliability applications, products with high reliability require a long time to obtain the failure data in normal life tests. Actually, zero-failure data is often detected in Type I Censoring life tests.

The early research about zero-failure data started by Bartholomew [1], who firstly used the test time as the estimate of the average life, which was obviously too small. Martz and Waller [12] developed a method for an exponential failure-time model and a gamma prior distribution on the failure rate. Chow and Shao $[2,3]$ used a regression model and the weighted least squares method for accessing the shelf-lives of drug products. Miller, Morell and Noonan [13] provided the formulae for the probability of failure with zero-failure data based on some assumptions of Bayesian prior distribution, and gave an example of failure rate estimation with zero-failure data. Han $[4,5]$ developed an E-Bayesian estimate method based on hierarchi- cal Bayesian estimation, which was proved to be feasible for zerofailure data. Liu [9] investigated the applications of E-Bayesian estimation for exponential life distribution. Based on the researches of E-Bayesian estimation, we introduce a reliability analysis method for the seekers, which is more convenient and effective for zero-failure data of exponential distribution.

The remainder of the paper is organized as follows. Section 2 presents a brief description of E-Bayesian method for the failure rate estimation of exponential distribution. In Section 3 we introduce the assumptions for reliability testing with zero-failure data. In Section 4 we provide an E-Bayesian method for exponential distribution with zero-failure data. In Section 5 we illustrate how the proposed E-Bayesian method can deal with zero-failure data in life testing, and compare it with different zero-failure analysis methods. In Section 6 We give some comments and conclusions.

\section{E-Bayesian estimation for the failure rate of exponen- tial distribution}

Exponential life distribution is suitable for the electronic products, so it is widely applied in the field of electronic reliability. For example, it is used as the life distribution of semiconductor devices 
both in Japanese industry standards and American military standards. The density function of exponential distribution is:

$$
f(t)=\lambda \exp (-\lambda t)
$$

where $t>0, \lambda>0$, and $\lambda$ is the failure rate of the exponential distribution.

Han introduced the definition of E-Bayesian estimation in [8]. Assume that $\hat{\lambda}(t)$ is a continuous function defined on the interval $R$,

and $t \in R$. If $\int_{\Omega}|\hat{\lambda}(t)| \pi(t) d t<\infty$, the definition of expected Bayesian (E-Bayesian) estimation is:

$$
\hat{\lambda}_{E B}=\int_{\Omega} \hat{\lambda}(t) \pi(t) d t
$$

where $\Omega$ is the interval of the hyper parameter $t, \pi(t)$ is the density function in $\Omega, \hat{\lambda}(t)$ is Bayesian estimation for $\lambda$. From the EBayesian definition of failure rate $\lambda$, we can obtain:

$$
\hat{\lambda_{E B}}=\int_{\Omega} \hat{\lambda}(t) \pi(t) d t=E_{t}[\hat{\lambda}(t)]
$$

We can see that $\hat{\lambda}_{E B}$ is the mathematical expectation of hyper parameter $t$ in the Bayesian estimation $\hat{\lambda}(t)$.

It is noticeable that E-Bayesian estimation is different from hierarchical Bayesian estimation. However, there are some connections between the E-Bayesian estimation and hierarchical Bayesian estimation, see $[5,8]$ for further details.

\section{Assumptions for zero-failure data}

Different kinds of censored data are often gathered in reliability and life tests. For Type I Censoring test, especially in the tests of high-reliability products with small samples, zero-failure data are frequently collected. With the development of technology, zero-failure data attracted wide attention, and the researches on zero-failure data needs intensive studies.

In reliability tests, we assume that the distribution function of product life $T$ is $F(t)$, follow the two steps:

- Take $n$ samples and divide them into $m$ groups. The number of the sample in the $i$ th group is $n_{i}, i=1,2,3, \ldots, m, \sum_{i=1}^{m} n_{i}=n$.

- Assume that each group starts testing at the same time 0 , the $i$ th group stops at time $t_{i}, 0<t_{1}<t_{2}<\ldots<t_{m}$, and no product fails during the whole test. Then $\left(t_{i}, n_{i}\right)$ is called zero-failure data.

The test starts at time 0 with $m$ group, group 1 stops testing until time $t_{1}$, group 2 stops testing until time $t_{2}$. It goes on until time $t_{m}$, group $m$ stops testing, when all tests come to the end. We can obtain:

$$
S_{j}=\sum_{i=j}^{m} n_{i}, \quad j=1,2,3, \ldots, m
$$

There is not any failure during the test, from time $t_{j}$ onwards, $S_{j}$ samples are still under test. So we can suggest that there are $S_{j}$ samples of which life is more than $t_{j}, j=1,2, \ldots, m$. lows:

According to the above, we can make some assumptions as fol-

-When the time of the reliability test is $t_{0}=0$, the failure rate of the product is 0 , which is $p_{0}=P(T \leq 0)=F(0)=0$.

- $S_{j}=\sum_{i=j}^{m} n_{i}, j=1,2,3, \ldots, m$, that means at time $t_{j}$, there are $S_{j}$

samples whose life are longer than $t_{j}, j=1,2, \ldots, m$.

- The failure rate at time $t_{j}$ is $p_{j}=P\left(T \leq t_{j}\right)$, $0<t_{1}<t_{2}<\ldots<t_{m}$. Then the reliability of the product at time $t_{j}$ is $R=1-p_{j}=P\left(T>t_{j}\right), p_{0}<p_{1}<\ldots<p_{m}$.

\section{E-Bayesian model for exponential distribution with zero-failure data}

If the life distribution of the product is exponential distribution, the density function is as follows:

$$
f(t)=\lambda \exp (-\lambda t), t>0
$$

where $\lambda$ is the failure rate of the exponential distribution, and $\lambda>0$.

Assume the prior distribution of $\lambda$ is a Gamma distribution, the density function is:

$$
\pi(\lambda \mid a, b)=\frac{b^{a}}{\Gamma(a)} \lambda^{a-1} \exp (-b \lambda)
$$

where $a$ and $b$ are both hyper parameters with $a>0, b>0, \lambda>0$ , and $\Gamma(a)=\int_{0}^{\infty} t^{a-1} e^{-t} d t$ is a Gamma function.

Usually the failure rate of a high quality product is less than that of a low quality product with the failure data, which fits for the reliability theory. According to that model, Xu and Liu [15] proposed a decreasing function for prior distribution of failure rate $\lambda$. The derivative of the density function $\pi(\lambda \mid a, b)$ is:

$$
\frac{d \pi(\lambda \mid a, b)}{d \lambda}=\frac{b^{a} \lambda^{a-2} \exp (-b \lambda)((a-1)-b \lambda)}{\Gamma(a)}
$$

It can be seen that when $0<a<1$ and $b>0$, from Eq. (6) one can find that the prior distribution $\pi(\lambda \mid a, b)$ is a decreasing function for $\lambda$. For Bayesian estimation, when $0<a<1$, the increasing of parameter $b$ makes the reliability robustness decreasing. Thus we set an upper bound $c$ for parameter $b$, then the range of $b$ is $0<b<c$ ( $c$ is a constant). Assuming the prior distribution of $a$ is $U(0,1)$ and that of $b$ is $U(0, c)$ [9]. So we can obtain the density functions of $a$ and $b$ as:

$$
\pi(a)=1(0<a<1), \pi(b)=\frac{1}{c}(0<b<c)
$$


In Type I Censoring tests of exponential distribution samples, if there are $X_{i}$ samples failed in test $i(i=1,2, \ldots, m), i$ is the number of Type I Censoring tests. Based on [10], the failure number $X_{i}$ is subject to Poisson distribution with the parameters $t_{i}, n_{i}$ and $\lambda$ :

$$
P\left\{X_{i}=r_{i}\right\}=\frac{\left(t_{i} n_{i} \lambda\right)^{r_{i}}}{\left(r_{i}\right) !} \exp \left(-t_{i} n_{i} \lambda\right)
$$

where $r_{i}=0,1, \ldots, n$, and $i=1,2, \ldots, m$.

The likelihood function of $\lambda$ is:

$$
L\left(X_{i} \mid \lambda\right)=\prod_{i=1}^{m} P\left\{X_{i}=r_{i}\right\}=\left[\prod_{i=1}^{m} \frac{\left(t_{i} n_{i} \lambda\right)^{r_{i}}}{\left(r_{i}\right) !}\right] \exp (-N \lambda)
$$

under zero-failure condition, which means $r_{i}=0, i=1,2, \ldots, m$, we can note that $L(0 \mid \lambda)=\exp (-N \lambda)$.

If the prior density function $\pi(\lambda \mid a, b)$ is exactly as Eq. (6), according to Bayes theory, the posterior density function of $\lambda$ is:

$$
\begin{aligned}
h(\lambda \mid 0)= & \frac{\pi(\lambda \mid a, b) L(0 \mid \lambda)}{\int_{0}^{\infty} \pi(\lambda \mid a, b) L(0 \mid \lambda) d \lambda}=\frac{\frac{b^{a}}{\Gamma(a)} \lambda^{a-1} \exp (-b \lambda) \exp (-N \lambda)}{\int_{0}^{\infty} \frac{b^{a}}{\Gamma(a)} \lambda^{a-1} \exp (-b \lambda) \exp (-N \lambda) d \lambda} \\
& =\frac{\lambda^{a-1} \exp [-(N+b) \lambda]}{\int_{0}^{\infty} \lambda^{a-1} \exp [-(N+b) \lambda] d \lambda}=\frac{(N+b)^{a}}{\Gamma(a)} \lambda^{a-1} \exp [-(N+b) \lambda]
\end{aligned}
$$

The Bayesian estimation of $\lambda$ under square loss is:

$\hat{\lambda}_{B}=\int_{0}^{\infty} \lambda h(\lambda \mid 0) d \lambda=\frac{(N+b)^{a}}{\Gamma(a)} \int_{0}^{\infty} \lambda^{a} \exp [-(N+b) \lambda] d \lambda=\frac{a}{N+b}$ is:

We can obtain E-Bayesian estimation of the failure rate $\lambda$, which

$$
\hat{\lambda}_{E B}=\frac{1}{c} \int_{0}^{c} \int_{0}^{1} \frac{a}{N+b} d a d b=\frac{1}{2 c} \int_{0}^{c} \frac{1}{N+b} d b=\frac{1}{2 c} \ln \frac{N+c}{N}
$$

where $N=\sum_{i=1}^{m} t_{i} n_{i},\left(t_{i}, n_{i}\right)$ is the zero-failure data in the life tests, $i=1,2, \ldots, m$.

\section{Experimental verification and model application}

In order to verify the proposed E-Bayesian estimation model, we set up a reliability test by subjecting specimens to a series of life tests under different working circumstances. Then the life data are collected and analyzed to obtain the life time of the specimens. The purpose of this experiment is to estimate the reliability of the seekers with a simplified estimation model for engineering applications.
The samples were tested in different test environments. None of them failed during the test, and these observations are shown in Table 5.1. Assume that differences between the test environments have no effect on the life time. We can assume that all the seekers were tested at the same time, thus we can obtain the zero-failure working time data of the observations, which are shown in Table 5.2.

According to Eq. (12), we have $N=\sum_{i=1}^{m} t_{i} n_{i}=2051$, and we can obtain the E-Bayesian estimation of the failure rate $\hat{\lambda}_{E B}$.

There are two methods to take zero-failure information into consideration. Han M. [6] proposed a model for $m+1$ Type I Censoring test, which is:

$$
t_{m+1}=t_{m}+\frac{1}{m-1} \sum_{i=2}^{m}\left(t_{i}-t_{i-1}\right), n_{m+1}=\left[\frac{1}{m} \sum_{i=1}^{m} n_{i}\right]
$$

where $\left[\frac{1}{m} \sum_{i=1}^{m} n_{i}\right]$ means rounding down for $\frac{1}{m} \sum_{i=1}^{m} n_{i}$. Then we can obtain $M=\sum_{i=1}^{m+1} t_{i} n_{i}$, and $\hat{\lambda}_{E B 1}=\frac{1}{2 c} \ln \frac{M+c}{M}$.

\begin{tabular}{|c|c|c|c|c|c|}
\hline \multirow{2}{*}{$\begin{array}{c}\text { Test } \\
\text { Sample }\end{array}$} & \multicolumn{5}{|c|}{ Working Time (h) } \\
\hline & $\begin{array}{c}\text { Test Envi- } \\
\text { ronment A }\end{array}$ & $\begin{array}{l}\text { Test Envi- } \\
\text { ronment B }\end{array}$ & $\begin{array}{l}\text { Test Envi- } \\
\text { ronment } \mathrm{C}\end{array}$ & $\begin{array}{l}\text { Test Envi- } \\
\text { ronment D }\end{array}$ & $\begin{array}{l}\text { Test Envi- } \\
\text { ronment } \mathrm{E}\end{array}$ \\
\hline a & 10 & 40 & 45 & 162 & 72 \\
\hline b & 10 & / & I & 162 & 68 \\
\hline c & 12 & 12 & 3 & 45 & 105 \\
\hline d & 10 & 13 & 3 & 50 & 102 \\
\hline
\end{tabular}

According to the average remaining life method, Wu [14] developed another model for $t_{m+1}$ with zero-failure data:

$$
t_{m+1}^{\prime}=t_{m}+\frac{1}{\lambda}, n_{m+1}=\left[\frac{1}{m} \sum_{i=1}^{m} n_{i}\right]
$$

Table 5.1 Working time of the seekers

Table 5.2 Zero-failure data of the tested seekers

\begin{tabular}{|c|c|c|c|}
\hline $\begin{array}{c}\text { Test } \\
\text { Sample }\end{array}$ & $\begin{array}{c}\text { Failure } \\
\text { Number }\end{array}$ & $\begin{array}{c}\text { Total Working Time } \\
\text { (Censoring Time } t_{i} \text { ) }\end{array}$ & $\begin{array}{c}\text { Cumulative Zero- } \\
\text { failure Number } \\
\text { (Test Sample } n_{i} \text { ) }\end{array}$ \\
\hline c & 0 & $177 \mathrm{~h}$ & 4 \\
\hline d & 0 & $178 \mathrm{~h}$ & 3 \\
\hline b & 0 & $240 \mathrm{~h}$ & 2 \\
\hline a & 0 & $329 \mathrm{~h}$ & 1 \\
\hline
\end{tabular}


Table 5.3 The results of E-Bayesian estimation for failure rate

\begin{tabular}{||c|c|c|c|c|c|c|c|c||}
\hline \hline$c$ & 300 & 500 & 1000 & 2000 & 3000 & 4000 & 5000 & 6000 \\
\hline$\hat{\lambda}_{E B} \times 10^{-4}$ & 2.2752 & 2.1815 & 1.9857 & 1.7015 & 1.5020 & 1.3523 & 1.2348 & 1.1395 \\
\hline$\hat{\lambda}_{E B 1} \times 10^{-4}$ & 1.5885 & 1.5415 & 1.4384 & 1.2771 & 1.1552 & 1.0591 & 0.9808 & 0.9155 \\
\hline$\hat{\lambda}_{E B 2} \times 10^{-4}$ & 0.3568 & 0.3428 & 0.3133 & 0.2695 & 0.2383 & 0.2145 & 0.1957 & 0.1804 \\
\hline$\hat{\lambda}_{H} \times 10^{-4}$ & 4.4515 & 4.2156 & 3.7409 & 3.0948 & 2.6687 & 2.3629 & 2.1307 & 1.9472 \\
\hline
\end{tabular}

Table 5.4 The results of E-Bayesian estimation for reliability

\begin{tabular}{|c|c|c|c|c|c|c|c|c||}
\hline$c$ & 300 & 500 & 1000 & 2000 & 3000 & 4000 & 5000 & 6000 \\
\hline$\hat{R}_{E B}$ & 0.9555 & 0.9573 & 0.9610 & 0.9665 & 0.9704 & 0.9733 & 0.9756 & 0.9774 \\
\hline$\hat{R}_{E B 1}$ & 0.9687 & 0.9696 & 0.9716 & 0.9748 & 0.9772 & 0.9790 & 0.9806 & 0.9819 \\
\hline$\hat{R}_{E B 2}$ & 0.9929 & 0.9932 & 0.9938 & 0.9946 & 0.9952 & 0.9957 & 0.9961 & 0.9964 \\
\hline$\hat{R}_{H}$ & 0.9148 & 0.9191 & 0.9279 & 0.9400 & 0.9480 & 0.9538 & 0.9583 & 0.9618 \\
\hline
\end{tabular}

where $\lambda$ is a unknown parameter, we use E-Bayesian estimation $\hat{\lambda}_{E B}$ instead of $\lambda$. Then we can obtain $M^{\prime}=\sum_{i=1}^{m} t_{i} n_{i}+t^{\prime}{ }_{m+1} n_{m+1}$, and $\hat{\lambda}_{E B 2}=\frac{1}{2 c} \ln \frac{M^{\prime}+c}{M^{\prime}}$.

As reported in [11], the range of $c$ is $300 \leq c \leq 6000$, which is reasonable in engineering practice. Based on Eq. (12), we calculate the values of $\lambda$ with different $c$, and compare with the hierarchical Bayesian estimation [7]. The results are shown in Table 5.3.

According to [9], the reliability of exponential distribution with zero-failure data $\left(t_{i}, n_{i}\right)$ is as follows:

$$
\hat{R}(t)=\exp (-\hat{\lambda t})
$$

where $t$ is the moment for estimating the product reliability under the exponential distribution. The results of E-Bayesian estimation for reliability $(t=200 \mathrm{~h})$ are shown in Table 5.4

These estimation results accord with the practical situation of the seekers. Based on the results, it can be inferred that after taking zero-failure data into consideration, the reliability estimation method of the products is significantly improved. Compared with the average remaining life method for zerofailure data, Eq. (13) makes the results more conservative, which is more acceptable in engineering applications.

\section{Concluding remarks}

In this paper, a reliability analysis method based on the E-Bayesian estimation for zero-failure data is proposed to estimate the reliability of seekers. By integrating the zero-failure information, the precision of estimation results of reliability increases greatly based on the hierarchical Bayesian estimation. Furthermore, the experiment results demonstrate that E-Bayesian method makes the calculation process easier and more effective for exponential distribution products. In addition, smaller $c$ makes the results more conservative in engineering practices.

However, there are still some problems with reliability analysis of zero-failure data. When using Bayesian model for analyzing zerofailure data, the influence of assumptions about the parameters on final results is obscure. In addition, appropriate parameters and models selections for engineering applications need a further investigation.

\section{Acknowledgement}

This research was supported by the National Natural Science Foundation of China under contract number 11272082.

\section{References}

1. Bartholomew D J. A problem in life testing. Journal of the American Statistical Association 1957; 52(279): 350-355, http://dx.doi. org/10.1080/01621459.1957.10501394.

2. Chow S C and Shao J. Test for batch-to-batch variation in stability analysis. Statistics in medicine 1989; 8(7): 883-890, http://dx.doi. org/10.1002/sim.4780080712.

3. Chow S C and Shao J. Estimating drug shelf-life with random batches. Biometrics 1991; 1071-1079, http://dx.doi.org/10.2307/2532659.

4. Han M and Ding Y. Synthesized expected Bayesian method of parametric estimate. Journal of Systems Science and Systems Engineering 2004; 13(1): 98-111, http://dx.doi.org/10.1007/s11518-006-0156-0.

5. Han M. Expected Bayesian estimation of failure probability and its character. Acta Mathematica Scientia 2007; 3: 013.

6. Han M. The synthesize hierarchical Bayesian estimation of failure rate of zero-failure data, Operations Research and Management Science 1999; 8(1): 1-5.

7. Han M. The hierarchical Bayesian estimation of failure-rate of exponential distribution of zero-failure data. Journal of Engineering Mathematics 1998; 15(4): 135-138.

8. Han M. E-Bayesian estimation and hierarchical Bayesian estimation of failure rate. Applied Mathematics A Journal of Chinese Universities 2008; 23(4): 399-407.

9. Liu Y F. Some applications of Bayes method in the study for the reliability of zero-failure data. China: Wenzhou University 2011.

10. Mao S, Tang Y and Wang L. Reliability Statistics. Beijing: Higher Education Press 2008.

11. Mao S. Statistical analysis of zero failure data. Mathematical Statistics and Applied Probability 1989; 4: 489-506. 
12. Martz Jr H F and Waller R A. Bayesian Zero-Failure (BAZE) reliability demonstration testing procedure. J. Qual. Technol 1979; 11(3).

13. Miller K W, Morell L J, Noonan R E, et al. Estimating the probability of failure when testing reveals no failures. IEEE Transactions on Software Engineering 1992; 18(1): 33-43, http://dx.doi.org/10.1109/32.120314.

14. Wu X. Inspection with errors. Chinese Journal of Applied Probability and Statistics 1993; 9(3): 310-318.

15. Xu T, Liu H and Chen Y. Synthetic expected Bayesian estimation of failure rate in the case of zero failure data. Journal of Applied Statistics and Management 2011; 30(4): 644-654.

\section{Yi-Chao YIN \\ Hong-Zhong HUANG \\ Weiwen PENG \\ Yan-Feng LI \\ Jinhua MI}

Institute of Reliability Engineering

University of Electronic Science and Technology of China

No. 2006, Xiyuan Avenue, West Hi-Tech Zone

Chengdu, Sichuan, 611731, P. R. China

E-mail: hzhuang@uestc.edu.cn 